\title{
Avaliação de indicadores de qualidade do solo sob alternativas de recuperação do solo no Nordeste Paraense $^{1}$
}

\author{
Débora Veiga de ARAGÃO², Cláudio José Reis de CARVALHO², Osvaldo Ryohei $\mathrm{KATO}^{2}$, Cleo Marcelo de \\ ARAÚJO², Maria Tereza Primo dos SANTOS², Moisés MOURÃO JÚNIOR²
}

\begin{abstract}
RESUMO
Os indicadores convencionais de fertilidade de solo, mais comumente utilizados, enfatizam o balanço ácido-base e o conteúdo de elementos químicos, mas não consideram adequadamente as propriedades biológicas do solo, responsáveis por grande parte do seu funcionamento. Os indicadores biológicos, ainda pouco difundidos, levam em consideração a atividade microbiana do solo que é mais sensível à dinâmica do solo. Em Marapanim-PA, e utilizando um desenho experimental inteiramente casualizado, com quatro repetiçóes, avaliou-se o comportamento dos indicadores do solo carbono e nitrogênio da biomassa microbiana, fosfatase ácida, matéria orgânica, carbono orgânico e fósforo disponível, em um solo com cultivo sequencial de mandioca e milho, preparo com corte-e-trituração da capoeira original. Os fatores corte-e-trituração, fosfato natural e adubação verde foram arranjados nos seguintes tratamentos: capoeira; testemunha; fosfato natural (FN); feijāo-de-porco [Canavalia ensiformis (L.) DC] (FP); FN + FP; FN + guandu [Cajanus cajan (L.) Millspaugh]. (G); FN + titônia [Tithonia diversifolia (Hemsley) A. Gray] (T); FP + G; FP + T. Em quatro épocas de amostragens, foram tiradas amostras compostas do solo $(0-10$ $\mathrm{cm}$ ) de cada parcela para análise dos indicadores. Os indicadores estudados foram influenciados pela época de amostragem do solo. Os indicadores fosfatase ácida, nitrogênio da biomassa microbiana e carbono da biomassa microbiana foram capazes de detectar os efeitos de maior número de tratamentos de recuperaçáo do solo testados, enquanto a matéria orgânica do solo foi o menos capaz. Ao longo do tempo, a resposta dos indicadores variou em função dos fatores estudados.
\end{abstract}

PALAVRAS-CHAVE: Corte-e-trituração, atributos do solo, fosfato natural, adubação verde, Amazônia.

\section{Evaluation of soil quality indicators under soil reclamation alternatives in Northeastern Pará State}

\begin{abstract}
The more commonly used traditional soil fertility indicators emphasize the acid-basic balance and the content of chemical elements, but do not consider adequately the biologic soil properties, largely responsible for soil functioning. The biologic indicators, not yet sufficiently used, take into consideration the microbial activity that is more sensible to soil dynamics. This study was carried out in Marapanim-PA and using a completely randomized plot design, with four replications, to evaluate the behavior of some indicators such as microbial biomass, acid phosphatase, soil organic matter, organic carbon and available phosphorus - in a soil cultivated with cassava and corn, and in which the secondary vegetation was prepared by slash-and-trituration practice. The slash-and-trituration, rock phosphate and green manure factors were arranged in the following treatments: secondary vegetation; control; rock phosphate (RP); wonderbean Canavalia ensiformis (L.) DC (W); $\mathrm{RP}+\mathrm{W} ; \mathrm{RP}+$ pigeonpea Cajanus cajan (L.) Millspaugh (P); RP + tithonia Tithonia diversifolia (Hemsley) A. Gray (T); W + $\mathrm{P} ; \mathrm{W}+\mathrm{T}$. In four season of sampling, soil samples were taken from the $0-10 \mathrm{~cm}$ layer of each parcel to measure the indicator values. The indicators studied were influenced by the time of soil sampling. The acid phosphatase, microbial biomass nitrogen and microbial biomass carbon soil indicators were capable of detecting the effects of a higher number of soil reclamation treatments, while soil organic matter was the least capable. With the passing of time, the response of the indicators varied according to the factors studied.
\end{abstract}

KEYWORDS: Slash-and-trituration, soil attribute, rock phosphate, green manure, Amazon.

\footnotetext{
1 Parte da tese de doutorado do primeiro autor. Universidade Federal Rural da Amazônia, Doutorado em Ciências Agrárias.

2 Embrapa Amazônia Oriental, Belém/PA. Travessa Dr. Enéas Pinheiro, s/no. CEP 66095-100 - Belém, PA - Brasil. E-mail do primeiro autor: dvaragao@cpatu.embrapa.br
} 


\section{INTRODUÇÃO}

O sistema de agricultura tradicional, com base no preparo de área com corte-e-queima da capoeira, utilizado há mais de um século no Nordeste Paraense, limita a produção agrícola por promover a perda de nutrientes e reduzir a fertilidade do solo, devido aos efeitos deletérios do fogo na vegetação (Kato et al. 2002).

Em contrapartida, a prática de preparo de área com cortee-trituração da vegetação evita que os nutrientes acumulados na biomassa aérea sejam perdidos por volatilização, erosão e lixiviação, mantendo assim a produtividade agrícola (Kato et al. 2002). Portanto, a adoção dessa prática contribui para a sustentabilidade agrícola, na medida em que são melhorados os atributos físicos, químicos e biológicos do solo, decisivos para o desenvolvimento das plantas e a vida da microbiota do solo (Doran e Parkin 1994).

A qualidade do solo é entendida como a capacidade de sustentar a produtividade biológica do ecossistema, mantendo o equilíbrio ambiental e promovendo a saúde de plantas e/ou animais e do próprio ser humano (Doran et al. 1996; Sposito e Zabel 2003). No entanto, avaliar a qualidade do solo requer o monitoramento de alguns parâmetros que variam com as mudanças no manejo ou fatores externos.

Recentemente tem crescido na comunidade científica o interesse por indicadores do funcionamento do sistema solo, baseados na atividade microbiana, que sozinhos ou em conjunto com outros indicadores convencionais, podem ajudar a orientar os produtores a manejarem seus solos de forma mais produtiva e sustentável.

As propriedades biológicas do solo, como biomassa microbiana, atividade enzimática e taxa de respiração constituem indicadores sensíveis às alteraçóes ambientais e servem como ferramenta para orientar o planejamento e avaliar as práticas de manejo do solo (Spadotto et al. 2004). Além desses, os indicadores químicos retratam parâmetros que são responsáveis pelos processos naturais do funcionamento do solo, como a matéria orgânica - que influência a liteira e a biomassa microbiana, o $\mathrm{pH}$ - a disponibilidade de nutrientes - e o conteúdo de nutrientes - a produção de biomassa.

Neste estudo, os indicadores carbono da biomassa microbiana (CBM), nitrogênio da biomassa microbiana (NBM), fosfatase ácida, matéria orgânica do solo (MOS), carbono orgânico $\left(\mathrm{C}_{\text {org }}\right)$ e fósforo disponível $\left(\mathrm{P}_{\text {disp }}\right)$, foram avaliados em diferentes tratamentos de recuperaçáo da fertilidade de solo, ao longo do tempo.

\section{MATERIAL E MÉTODOS}

Os indicadores foram avaliados nas parcelas de um experimento que visou comparar algumas alternativas de recuperação da fertilidade de solo de sistemas agrícolas de subsistência, cuja metodologia é descrita a seguir.

A área experimental fica numa propriedade da comunidade São João, município de Marapanim-PA, Nordeste Paraense, situada entre as latitudes 0 $56^{\prime} 24^{\prime \prime}$ e 1०4'12" S e as longitudes 47034'48" e 47039'36" WGr. De acordo com a classificação de Köppen, o clima é quente e úmido, do tipo Ami. De julho de 2006 a julho de 2008, a temperatura média da área do estudo foi de $27^{\circ} \mathrm{C}$. As chuvas se concentraram nos meses de janeiro a junho em 2007 e de dezembro a junho em 2008, com média mensal de 295 e $319 \mathrm{~mm}$, respectivamente. Nos meses mais secos a precipitaçấo média foi de 52 e $35 \mathrm{~mm}$, respectivamente.

O solo predominante é o Latossolo Amarelo, textura média, de baixa fertilidade, com $2 \mathrm{mg}$ de $\mathrm{P} \mathrm{kg}^{-1}$ de solo e $\mathrm{pH}$ ácido $(5,8)$.

Em junho de 2006, uma área de 1,5 ha de capoeira de 18 meses foi manualmente derrubada e triturada, e a biomassa resultante, de $8,5 \pm 1,6 \mathrm{t} \mathrm{MS} \mathrm{ha}^{-1}$, foi uniformemente distribuída sobre o terreno para formação do mulch, conforme a prática de preparo do solo de corte-e-trituração. Nenhuma operaçáo mecânica de preparo de solo foi realizada na área.

As alternativas de recuperação foram avaliadas em cultivos sucessivos, de mandioca (Manihot esculenta Crantz), variedade local Inha, e de milho (Zea mays L), variedade BR 5102. Os fatores experimentais prática de corte-e-trituração, fosfato natural e adubação verde com feijão-de-porco (Canavalia ensiformis (L.) DC.), guandu (Cajanus cajan (L.) Millspaugh.) e titônia (Tithonia diversifolia (Hemsley) A. Gray) foram testados por meio dos seguintes tratamentos: capoeira (CAP), testemunha (TEST), fosfato natural (FN), feijáo-de-porco (FP), FP + FN, FN + guandu (G), FN + Titônia (T), FP + G e FP + T. À exceçáo das parcelas do tratamento capoeira, a vegetaçáo original foi submetida ao corte-e-trituração, como prática de preparo de área para plantio.

O delineamento experimental foi inteiramente casualizado, com nove tratamentos e quatro repetiçóes; as parcelas experimentais foram de $10 \mathrm{~m} \times 10 \mathrm{~m}$, com área útil de $5 \mathrm{~m}$ x $5 \mathrm{~m}$.

A mandioca foi plantada no espaçamento de $1 \mathrm{~m} \times 1 \mathrm{~m}$, em plantio direto. As espécies usadas na adubação verde foram plantadas intercaladamente e na mesma época da mandioca. As sementes de feijão-de-porco foram plantadas em espaçamento de $0,5 \mathrm{~m} \times 0,5 \mathrm{~m}$ e as de guandu em espaçamento de $1,0 \mathrm{~m} \mathrm{x}$ $0,5 \mathrm{~m}$. As estacas de titônia foram plantadas em espaçamento de $1,0 \mathrm{~m} \times 0,5 \mathrm{~m}$. O fosfato natural (Arad), com $33 \%$ de $\mathrm{P}_{2} \mathrm{O}_{5}$ solúvel, foi aplicado a lanço, após o plantio, na dose de $99 \mathrm{~kg}$ de $\mathrm{P}_{2} \mathrm{O}_{5}$ ha $^{-1}$.

Após a colheita da mandioca, o milho foi plantado no espaçamento de $1 \mathrm{~m} \mathrm{x} 1 \mathrm{~m}$, intercaladamente às rebrotas do 
guandu e da titônia. Uma semana antes do plantio do milho, foi feita uma nova aplicação do fosfato natural.

Em julho de 2006, antes de qualquer interferência nas parcelas, procedeu-se a primeira amostragem da camada superficial do solo $(0-10 \mathrm{~cm})$. Ao longo do estudo, efetuaramse mais três amostragens na mesma profundidade: em setembro e dezembro de 2007, e em julho de 2008, para determinar CBM, NBM, fosfatase ácida, MOS, $\mathrm{C}_{\text {org }}$ e $\mathrm{P}_{\text {disp }}$.

Os métodos usados na determinação são descritos em Baker (1976) para CBM, Embrapa (1997) para NBM, MOS, $\mathrm{C}_{\text {org }}$ e $\mathrm{pH}$, Vance et al. (1987) para fosfatase ácida e Olsen $e t$ al. (1954) para $\mathrm{P}_{\text {disp. }}$.

Os dados experimentais foram analisados no programa Statistics, versão 8.0 (Statsoft, 2007). As médias foram comparadas pelo teste Tukey, ao nível de 5\%.

\section{RESULTADOS E DISCUSSÃO}

\section{Carbono e nitrogênio da biomassa microbiana (CBM e NBM)}

Os únicos tratamentos em que o CBM manteve-se constante, ao longo das amostragens, foram testemunha e fosfato natural (Figura 1). Há evidências de que o distúrbio na estrutura do solo e o impacto na qualidade da matéria orgânica ocasionem uma drástica queda no CBM (Cerri et al. 1985), da mesma forma que as mudanças de estação do ano alteram esse indicador (Theodoro et al. 2003).

Ao longo das amostragens, a resposta mais característica do CMB foi uma marcante queda da primeira para a segunda amostragem (setembro/2007), época de menor precipitaçáo pluvial (Figura 1). Desse ponto em diante, configuraram-se duas trajetórias: a) estabilização ao longo das amostragens seguintes, nos tratamentos fosfato natural com feijāo-de-porco, fosfato natural com guandu, feijāo-de-porco com guandu e feijão-de-porco com titônia; e b) recuperaçáo dos valores ao longo das amostragens seguintes, no tratamento capoeira, quando a precipitação pluvial aumentou, confirmando os achados de Sampaio (2008) que mostram um aumento do CBM com o aumento das chuvas em condição natural de crescimento da vegetação sucessional.

Nos tratamentos testemunha e fosfato natural, o CBM manteve-se estável em todas as amostragens. Diferentemente, nos tratamentos feijão-de-porco e fosfato natural com titônia, esse indicador manteve-se estável da primeira amostragem até a terceira, ocorrendo uma elevaçáo na última amostragem.

À exceçâo do tratamento fosfato natural com feijão-deporco, em que esse indicador diminuiu estatisticamente da primeira para a última amostragem, os demais se mantiveram estáveis. Dessa forma, é razoável admitir que o corte-etrituração por si só pode ser uma alternativa aceitável de manutenção do CBM do solo. Para Vasconcellos et al. (1999), resíduos vegetais deixados na superfície do solo favorecem a imobilizaçáo do carbono pela biomassa.

O único tratamento em que o NBM manteve-se constante, ao longo das amostragens, foi a capoeira (Figura 1).

No caso dos tratamentos feijáo-de-porco, feijáo-de-porco com guandu e feijáo-de-porco com titônia, o aumento desse indicador na segunda amostragem, mês de menor precipitação, pode ser atribuído à maior oferta de detritos e ao aumento do $\mathrm{N}$ mineral no solo. Além do mais, o déficit hídrico diminui a produção de biomassa das plantas e dificulta o seu florescimento, diminuindo a demanda de N (Rosa et al. 2005; Perez et al. 2005).

Num balanço final, o NBM diminuiu significativamente do início para o final do estudo nos tratamentos testemunha, fosfato natural com guandu e fosfato natural com titônia, diferentemente dos demais, em que esse indicador manteve-se estável da primeira para a última amostragem.

Por sua capacidade de produção de biomassa e fixação de $\mathrm{N}$ atmosférico, as leguminosas guandu (Seiffert e Thiago

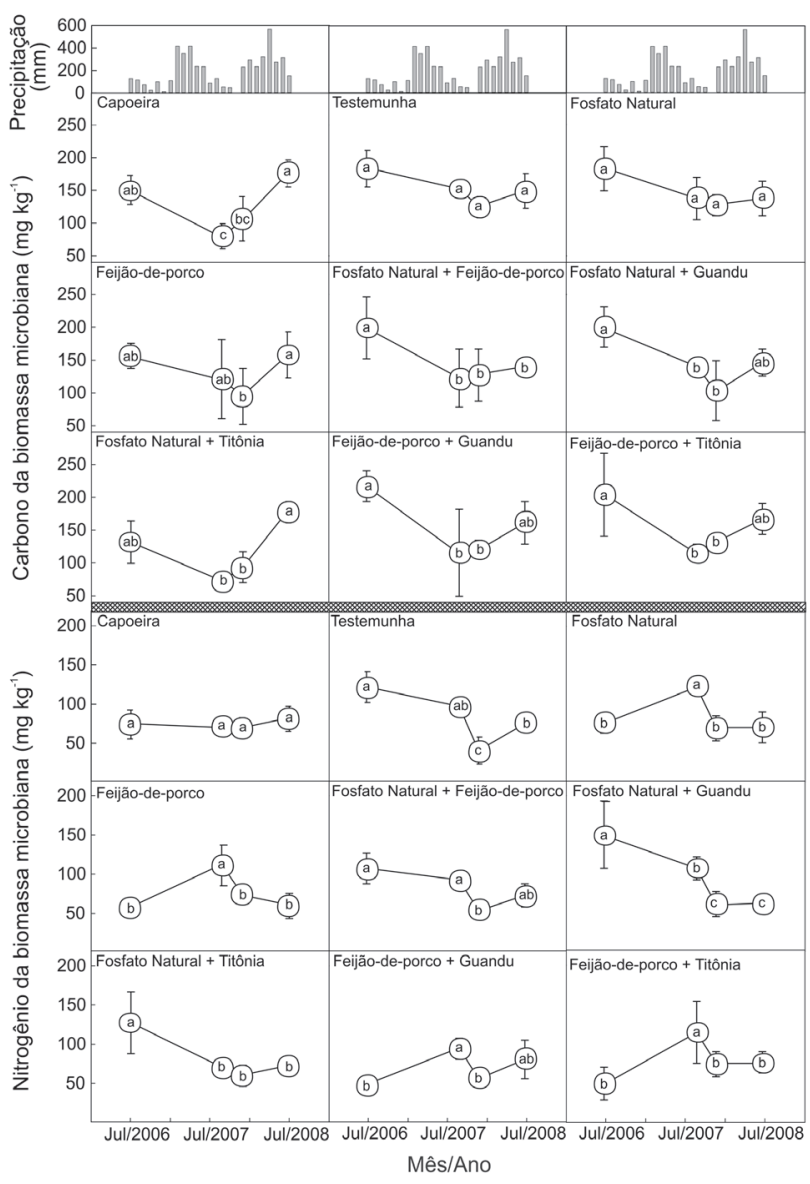

Figura 1 - Carbono e nitrogênio da biomassa microbiana na profundidade 0-10 cm, comunidade São João, município de Marapanim, estado do Pará. 
1983) e feijão-de-porco (Lopes 1998) tem sido recomendadas para adubação verde, contribuindo no metabolismo do $\mathrm{N}$ da atividade microbiana. Contudo, as respostas do indicador NBM neste estudo corroboram consistentemente com essa informação apenas no caso do feijão-de-porco.

\section{Fosfatase ácida}

A fosfatase ácida variou significativamente entre amostragens e em todos os tratamentos testados (Figura 2). Isso concorda com as evidências de que a atividade termolábil desta enzima varia de acordo com o clima (Portes 1988).

A resposta da fosfatase ácida, ao longo das amostragens, configurou quatro trajetórias (Figura 2). Na primeira, permaneceu estável da primeira até a terceira amostragem, elevando-se daí até o final, caso do fosfato natural, fosfato natural com guandu e fosfato natural com titônia. $\mathrm{Na}$ segunda trajetória, permaneceu estável da primeira para a segunda amostragem, desta decresceu até a terceira, subindo em seguida, no caso do feijão-de-porco e feijão-de-porco com fosfato natural. $\mathrm{Na}$ terceira, ocorreu uma elevação da primeira para a segunda amostragem, uma estabilidade da segunda para a terceira e uma elevação desta para a última, no caso do tratamento capoeira e feijão-de-porco com titônia. $\mathrm{Na}$ última, observou-se uma elevação da primeira para a segunda amostragem e um decréscimo desta para a terceira e uma elevação até o final, no caso da testemunha e feijão-deporco com guandu.

Dos tratamentos testados, apenas no tratamento fosfato natural com titônia não se observou elevação significativa do nível da fosfatase ácida, do início ao final do estudo. Como a fosfatase ácida é importante na disponibilização do P, é razoável se esperar que esse indicador aumente com o desenvolvimento

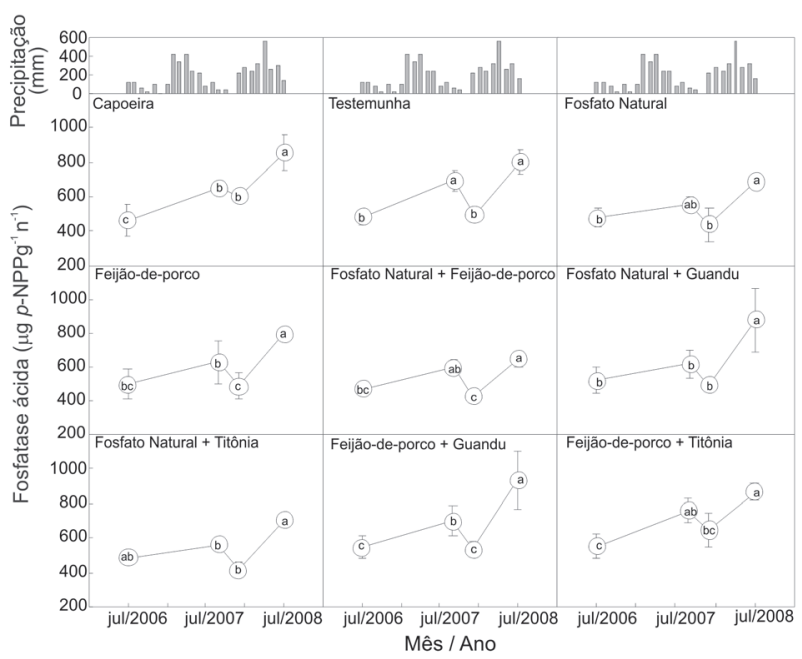

Figura 2 - Fosfatase ácida do solo na profundidade 0-10 cm, comunidade São João, município de Marapanim, estado do Pará. das plantas sucessionais (Portes 1988; Oliveira et al. 1999) e, possivelmente, com as demandas dos cultivos que se sucederam ao longo do estudo.

No tratamento capoeira, o significativo aumento da fosfatase ácida ao final do estudo pode ser justificado pela condição microclimática características desse sítio ou pela dinâmica de crescimento da própria vegetação.

\section{Matéria orgânica do solo (MOS)}

Ao longo das amostragens, os únicos tratamentos em que a MOS variou foram os com feijão-de-porco e guandu e com feijão-de-porco e titônia (Figura 3).

As respostas desse indicador, ao longo do estudo, podem ser representadas por três comportamentos (Figura 3). No primeiro, ocorreu uma elevação da primeira para a terceira amostragem, permanecendo estável até o final, no caso do feijão-de-porco com guandu. No segundo, houve uma estabilidade da primeira para a segunda amostragem, reduzindo a partir desta até o final, no caso do tratamento com feijão-de-porco e titônia. No último, o comportamento foi estável ao longo de todo o estudo, no restante dos tratamentos, incluindo o tratamento testemunha (corte-e-trituração). Como constatado, a prática de corte-e-trituração, mesmo numa capoeira bastante jovem, manteve a MOS, diferente do sistema mecanizado que normalmente reduz esse indicador (Souza et al. 2006). Segundo Trindade et al. (2009), a idade da capoeira influencia diretamente seu efeito na MOS.

Na comparaçáo do início com o final do período estudado, apenas o feijão-de-porco com guandu possibilitou aumento significativo nesse indicador. Possivelmente isso pode ser atribuído à biomassa das duas leguminosas.

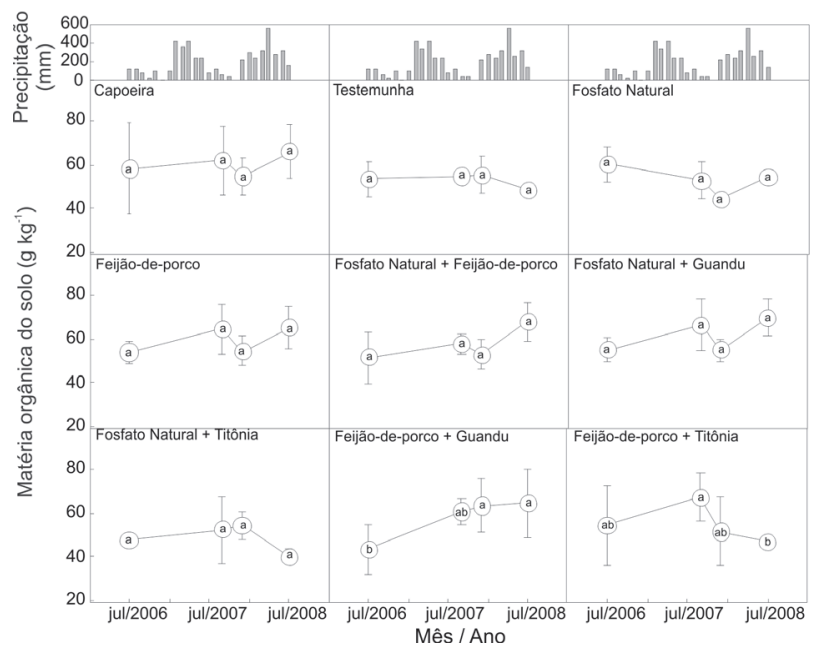

Figura 3 - Matéria orgânica do solo na profundidade 0-10 cm, comunidade São João, município de Marapanim, estado do Pará 


\section{Carbono orgânico $\left(\mathrm{C}_{\text {org }}\right)$}

Ao longo das amostragens, os tratamentos em que o $\mathrm{C}_{\text {org }}$ não variou foram capoeira, feijão-de-porco, feijão-de-porco com guandu e fosfato natural com guandu (Figura 4). Já na testemunha, observou-se uma estabilização da primeira até a terceira amostragem, elevando-se até a quarta. Nos tratamentos fosfato natural, fosfato natural com titônia e feijão-de-porco com titônia, esse indicador decresceu significativamente da primeira para a segunda amostragem, seguindo-se de uma estabilização nas demais. Nos tratamentos fosfato natural com feijáo-de-porco o $\mathrm{C}_{\text {org }}$ decresceu da primeira para a segunda amostragem, aumentando até a última. Este comportamento pode ter sido motivado pela menor precipitação, com a provável redução da produção de biomassa vegetal que está associada ao $\mathrm{C}_{\text {org }}$ do solo (USDA 2009).

Em geral, nenhum tratamento foi capaz de elevar o nível final de $\mathrm{C}_{\text {org }}$ em relaçáo à condição inicial (Figura 4); pelo contrário, os tratamentos fosfato natural e fosfato natural com titônia proporcionaram um balanço negativo.

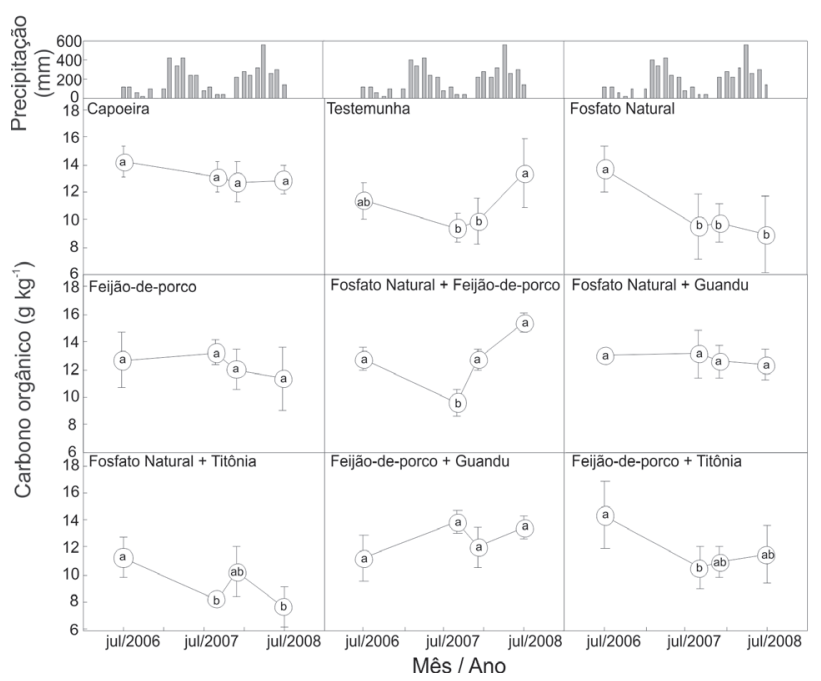

Figura 4 - Carbono orgânico do solo na profundidade 0-10 cm, comunidade São João, município de Marapanim, estado do Pará.

\section{Fósforo disponível $\left(\mathrm{P}_{\text {disp }}\right)$}

Ao longo das amostragens, os únicos tratamentos em que o $\mathrm{P}_{\text {disp }}$ variou foram fosfato natural, fosfato natural com guandu, fosfato natural com titônia e feijão-de-porco com guandu (Figura 5).

A resposta do indicador $\mathrm{P}_{\text {disp }}$ mostrou três tendências (Figura 5), ao longo do estudo. A primeira foi caracterizada por uma elevação da primeira para a segunda amostragem (setembro/2007), mês de menor precipitação, permanecendo inalterada até o final nos tratamentos fosfato natural, fosfato natural com guandu e fosfato natural com titônia. Já a segunda apresentou uma elevação gradativa da primeira para a última amostragem, no feijão-de-porco com guandu. A terceira tendência permaneceu inalterada ao longo do estudo, caso dos tratamentos restantes.

Todos os tratamentos com fosfato natural elevaram significativamente, em algum momento, os níveis de $\mathrm{P}_{\text {disp. }}$. Segundo Moltocaro (2007), em cultivo de arroz, o guandu, quando adubado, eleva o teor de $\mathrm{P}_{\text {disp }}$ no solo. Em condiçóes de preparo do solo por corte-e-trituração da capoeira, tem sido comprovada a necessidade da aplicaçáo do fosfato natural com o objetivo de fornecer $\mathrm{P}$ aos cultivos agrícolas (Kato et al. 2000).

$\mathrm{Na}$ comparaçáo do início com o final do estudo e mesmo considerando a exportação de nutrientes via cultivos, apenas o fosfato natural com guandu e feijão-de-porco com guandu elevaram o nível de $\mathrm{P}_{\text {disp }}$ no solo, o que é muito importante tendo em vista a carência desse nutriente nos solos tropicais.

Em alguns estudos, a titônia tem mostrado maior capacidade de acumular P nos seus tecidos do que a maioria das plantas (Cong e Merckx 2005; Ikerra et al. 2006), no entanto, neste estudo, isso não pôde ser comprovado.

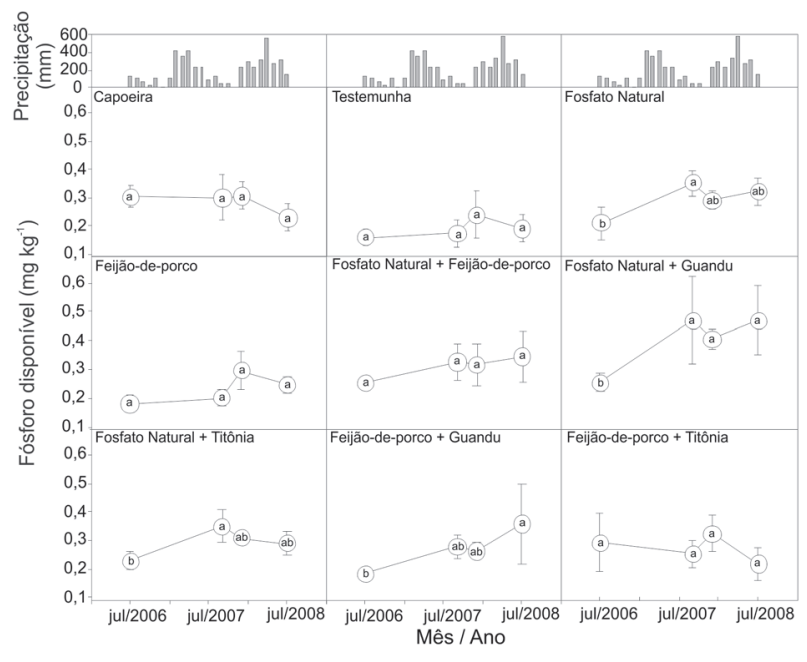

Figura 5 - Fósforo disponível do solo na profundidade 0-10 cm, comunidade São João, município de Marapanim, estado do Pará.

\section{Resposta dos indicadores aos fatores de recuperação do solo}

Para se verificar o efeito do fator corte-e-trituração, comparou-se a variação dos indicadores da primeira amostragem (julho/2006) para a última (julho/2008) nos tratamentos testemunha (corte-e-trituração) e capoeira (Figuras 1 a 5). A única discordância foi representada pela diminuição do NBM no corte-e-trituração e estabilidade na capoeira, indicando que o fator corte-e-trituração prejudica 
esse indicador, o que contraria os achados de Huang et al. (2008).

É possível que o impacto negativo do corte-e-trituração nesse indicador seja resultado, entre outros fatores, do aumento da temperatura (Almeida et al. 2009) e da relaçáo C:N do solo (Tiquia et al. 2002) que ocorre devido ao mulch resultante.

De mesmo modo, com respeito ao fator fosfato natural, comparou-se a variação dos indicadores nos tratamentos fosfato natural e testemunha (Figuras 1 a 5). Neste caso, houve duas discordâncias: (1) estabilidade do NBM no fosfato natural e diminuição na testemunha; e (2) diminuição do $\mathrm{C}_{\text {org }}$ no fosfato natural e estabilidade no testemunha. Isso indica que o fosfato natural favorece o NBM e prejudica o $\mathrm{C}_{\text {org }}$. Segundo Amado et al. (2001) a qualidade e quantidade do mulch afeta o $\mathrm{C}_{\text {org }}$.

No caso da adubação verde, usaram-se dois contrastes de tratamentos: feijão-de-porco com guandu versus testemunha, e feijão-de-porco com titônia versus testemunha (Figuras 1 a 5). No primeiro contraste, ocorreram duas discordâncias: (1) estabilidade do NBM no feijão-de-porco com guandu e diminuiçáo no testemunha; e (2) aumento da MOS e do $\mathrm{P}_{\text {disp }}$ no feijāo-de-porco com guandu e estabilidade no testemunha. Isso pode sugerir que a adubação verde, representada por essa combinação de leguminosas, favorece esses indicadores. A MOS está relacionada a importantes processos do solo como infiltração e retençáo de água (Rawls et al. 2003), CTC (Stevenson 1994) e disponibilidade de nutrientes (Cheng 1997). Duarte et al. (2010) verificaram que guandu e feijãode-porco aumentam as taxas de $\mathrm{P}$ remanescente no solo, uma vez que a MOS facilita o aproveitamento do $P$ pelas culturas (Tirloni et al. 2009).

Quanto ao contraste feijáo-de-porco com titônia versus testemunha, o único comportamento discordante foi a estabilidade do NBM no feijáo-de-porco com titônia e diminuição no testemunha (Figuras 1 a 5). Isso também confirma a contribuição dessa combinação de plantas adubadoras de solo na manutenção desse indicador através do estímulo ao metabolismo do N (Seiffert e Thiago 1983; Lopes 1998).

\section{CONCLUSÕES}

De modo geral e em variado grau, os indicadores da qualidade de solo carbono da biomassa microbiana, nitrogênio da biomassa microbiana, fosfatase ácida, matéria orgânica, carbono orgânico e fósforo disponível foram influenciados pela época de amostragem do solo.

Entre os indicadores estudados, com a fosfatase ácida, o nitrogênio da biomassa microbiana e o carbono da biomassa microbiana pode-se detectar os efeitos de maior número de tratamentos de recuperaçáo do solo testados, enquanto que com o indicador matéria orgânica do solo a detecção foi menor.

Num balanço final, os principais impactos nos indicadores, em função dos fatores de recuperação do solo foram: redução do nitrogênio da biomassa microbiana no corte-e-trituração e estabilidade no fosfato natural e adubaçáo verde, reduçáo do carbono orgânico no fosfato natural, e aumento da matéria orgânica do solo e fósforo disponível na adubação verde.

\section{AGRADECIMENTOS}

Os autores agradecem aos assistentes de campo Ednaldo Nascimento e Josie Helen, e aos assistentes de laboratório Ivanildo Trindade, Neusa Ferreira, Helieth, Déia, Jorge e Fabiano.

\section{BIBLIOGRAFIA CITADA}

Almeida, D.; Klauberg Filho, O.; Felipe, A.F.; Almeida, H.C. 2009. Microbial carbon, nitrogen and phosphorus on soil under different mulchings in organic apple orchard in southern of Brazil. Bragantia, 68(4): 1069-1077 (in Portuguese, with abstract in English).

Amado, T.J.C.; Bayer, C.; Eltz, F.L.F.; Brum, A.C.R. 2001. Potential of cover crops to sequester carbon and increase soil nitrogen content, under no-tillage system, improving environmental quality. Revista Brasileira de Ciência do Solo, 25: 189-197 (in Portuguese, with abstract in English).

Baker, K.F. 1976. The determination of inorganic carbon in soil using a probe-calorimeter. Laboratory practice, 15: 82-83.

Cerri, C.C.; Volkoff, B.; Eduardo, B.P. 1985. Deforestation effect on microbial biomass of a yellow latosol from Amazonic area, Brazil. Revista Brasileira de Ciência do Solo, 9(1): 1-4 (in Portuguese, with abstract in English).

Cheng, B.T. 1997. Soil organic matter as a plant nutrient. p. 31-39. In: Symposium on soil organic matter studies, Vienna. Soil organic matter studies. Austria: IEA.

Cong, P.T. and Merckx, R. 2005. Improving P availability in two upland soil of Vietnam using Tithonia diversifolia H. Plant and Soil, 269(1/2): 11-23.

Doran, J.W. and Parkin, T.B. 1994. Defining and assessing soil quality, p. 1-20. In: Doran, J.W.; Celeman, D.C.; Bezdicek, D.F.; Stewart, B.A. (Eds.) Defining soil quality for a sustainable environment. Madison, SSSA, (Special, 35).

Doran, J.W.; Sarrantonio, M.; Liebig, M.A. 1996. Soil health and sustainability. Advances in Agronomy, 56: 2-54.

Duarte, R.F.; Fernandes, L.A.; Sampaio, R.A.; Santos, L.D.T.; Lazo, J.A.; Silva, H.P. da; Carneiro, J.P. 2010. Green manure effect following crops under North Minas Gerais conditions. 4pp. Reunião Brasileira de Fertilidade do Solo e Nutrição de Plantas, 29. Guarapari - ES (in Portuguese). 
Embrapa. 1999. Manual of chemical analysis of soil, plants and fertilities / CNPS, CNPTIA. 1 Ed - Brasília. 370pp. (in Portuguese).

Huang, Z.; Xu, Z.; Chen, C. 2008. Effect of mulching on labile soil organic matter pools, microbial community function diversity and nitrogen transformations in two hardwood plantations of subtropical Australia. Apllied Soil Ecology, 40(2): 229-239.

Ikerra, S.I.; Semu, E.; Mrema, J. 2006. Combining Tithonia diversifolia and minjingu phosphate rock for improvement of $\mathrm{P}$ availability and maize grain yields on chromic acrisol in Morogoro, Tanzania. Nutrient Cycling in Agroecosystems, 76(23): 249-260.

Kato, M.S.A.; Kato, O.R.; Denich, M.; Vlek, P.L.G. 2000. Phosphorus availability in a mulch system in Eastern Amazonia. German-Brazilian Workshop on Neotropical Ecosystems Achievements and Prospects of Cooperative Research. Hamburg, CD-ROOM.

Kato, O.R.; Kato, M.S.A.; Jesus, C.C.; Rendeiro, A.C. 2002. Preparation timing area and corn plantation in slash-and-trituration system in Igarape-açu county. Belém: Embrapa Amazônia Oriental, (Comunicado Técnico, 64). 3pp (in Portuguese).

Lopes, O.M.N. 1998. Wonderbean in the soil with black piper. Belém: Embrapa-CPATU, (Circular Técnica, 74). 4pp (in Portuguese).

Moltocaro, R.C.R. 2007. Pigeon-pea and mycorrhiza for phosphate rock utilization by rice under greenhouse conditions. Dissertação de Mestrado. Agricultura Tropical e Subtropical, Instituto Agronômico. Campinas, São Paulo. 65pp (in Portuguese, with abstract in English).

Oliveira, I.P.O.; Thung, M.D.; Souza, C.M.R.; Santos, R.M. 1999. Activity of acid phosphatese in common bean and its correlation with some parameters of plant growth. Pesquisa Agropecuária Tropical, 29(2): 43-49 (in Portuguese, with abstract in English).

Olsen, S.R.; Cole, C.V.; Watanabe, F.S.; Dean, L.A. 1954. Estimation of available phosphorus in soil extraction with sodium bicarbonate. Washington: USDA, 19pp. (Circular, 939).

Perez, K.S.S.; Ramos, M.L.G.; Mcmanus, C. 2005. Microbial biomass nitrogen in soil cultivated with soybean, under different management systems, in the Cerrado. Pesquisa Agropecuária Brasileira, 40(2): 137-144. (in Portuguese, with abstract in English).

Portes, T.A. 1988. Ecophysiology, p. 125-156. In: Zimmermann, M.J.O.; Rocha, M.; Yamada, T. (Eds.). Bean culture: facts that affect the productivity. Piracicaba: Associação Brasileira para Pesquisa da Potassa e do Fosfato (in Portuguese).

Rawls, W.J.; Pachepsky, Y.A.; Ritchie, J.C.; Sobecki, T.M.; Bloodworth, H. 2003. Effect of soil organic carbon on soil water retention. Geoderma. 116: 61-76.

Rosa, J.R.; Lanna, A.C.; Ferraz, D.M.M.; Godoy, S.G.; Rabelo, V.C.; Mourão, V.C.; Palma, F.R.; Guardiola, M.F.; Ramos, M.L.G.; Heinemann, A.B.; Moreira, J.A.A.; Didonet, A.D. 2005. Soil microbial biomass nitrogen under common bean (Phaseolus vulgaris L.) organic crop, p.1030-1033. Congresso Nacional de Pesquisa de Feijáo, 8. Goiânia. Anais ... Santo Antônio de Goiás: Embrapa Arroz e Feijão, (Documentos, 182) (in Portuguese).
Sampaio, I.C.G. 2008. Carbon biogeochemistry in soil plots under trituration, burn and secondary vegetation. Dissertação de Mestrado, Universidade Federal do Pará / Museu Paraense Emílio Goeldi / Embrapa Amazônia Oriental, Belém, Pará. 82 pp (in Portuguese, with abstract in English).

Seiffert, N.F.; Thiago, L.R.L. 1983. Leguminous plots: forage crop for protein production. Campo Grande: Embrapa Gado de Leite. 51pp (Circular Técnica, 13) (in Portuguese).

Souza, Z.M.; Beutler, A.N.; Prado, R.M.; Bento, M.J.C.B. 2006. Effect of sugarcane harvest systems in the physical attributes of an Oxisol. Cientifica, 34(1): 31-38 (in Portuguese, with abstract in English).

Spadotto, C.A.; Gomes, M.A.F.; Luchini, L.C.; Andréa, M.M. 2004. Agrotoxics environmental risks monitoring: principles and recommendations. Jaguariúna: Embrapa Meio Ambiente. 29pp (Documentos, 42) (in Portuguese).

Sposito, G. and Zabel, A. 2003. The assessment of soil quality. Geoderma, 114(3/4): 143-144.

Stevenson, F. J. 1994. Humus chemistry: genesis, composition and reaction. 2ed. New York: John Wiley and Sons, 496 pp.

Statsoft, Inc. 2007. Statistica (data nalsis software system), versão 8.0, 2007.

Theodoro, V.C.A.; Alvarenga, M.I.N.; Guimarães, R.J.; Mourão Júnior, M. 2003. Microbial biomass carbon and mycorrhiza in soil under native wood and coffee agroecosystems. Acta Scientiarum: Agronomy, 25(1): 147-153 (in Portuguese, with abstract in English).

Tiquia, S.M.; Lloyd, J.; Herms. D.A.; Hoitink, H.A.J.; Michel JR, F.C. 2002. Effects of mulching and fertilization on soil nutrients, microbial activity and rhizosphere bacterial community structure determined by analysis of TRFLPs of PCR-amplified 16S rRNA genes. Applied Soil Ecology, 21: 31-48.

Tirloni, C.; Vitorino, A.C.T.; Novelino, J.O.; Tirloni, D.; Coimbra, D.S. 2009. Phosphorus availability due to additions of liming and soil bioactivator. Ciência e Agrotecnologia, 33(4): 977-984 (in Portuguese, with abstract in English).

Trindade, E.F.S.; Rodrigues, T.E.; Carvalho, E.J.M. 2009. Organic matter and phisical characteristics of yellow argissol distrofic in northeast of Para State, Brazil. Amazônia: Ciência e Desenvolvimento, 5(9): 187-198 (in Portuguese, with abstract in English).

Usda. 2009. Soil quality indicators: total organic carbon. USDA Natural Resources Conservation Service. 2pp.

Vance, E.D.; Brookers, P.P.; Jenkinson, D.S. 1987. An extraction method for measuring soil microbial biomass C. Soil Biolog and Biochemistry, 19: 703-707.

Vasconcellos, C.A.; Campolina, D.C.A.; Santos, F.G.; Exel Pitta, G.V.; Marriel, I.E. 1999. Soybean and biomass carbon response to residues of five sorghum. Revista Brasileira de Ciência do Solo, 23: 69-77 (in Portuguese, with abstract in English).

Recebido em 29/11/2010

Aceito em 30/04/2011 
